\title{
Synthesis and Characterization of Biodiesel from Waste Cooking Oil and Virgin Oil
}

\author{
S. T. Aly*, Sabah M. Farouk, Kareem H. Mokhtar, Yasmine E., Mai E., Nada E., Menna A. and Fatma R. \\ Chemical Engineering Department, \\ Egyptian Academy for Engineering and Advanced Technology, \\ Cairo, Egypt
}

\begin{abstract}
Biodiesel was produced from waste cooking oil and virgin oil through transesterification reaction in batch process. Methanol to oil molar ratio was 6:1 and $\mathrm{KOH}$ was used as catalyst .The reaction temperature was $60^{\circ} \mathrm{C}$ with $250 \mathrm{rpm}$ mechanical stirring. Acid value (AV) was determined; it was $4.48 \mathrm{mgKOH} / \mathrm{g}$ oil for waste oil and 0.2 for virgin oil. Functional groups in the produced biodiesel samples were determined using infrared spectroscopy (IR). The viscosity, density, flash point and calorific value were measured. The specifications of biodiesel products based on these parameters meet European Committee for Standardization EN 14214.).
\end{abstract}

Keywords-Biodiesel, Waste Cooking Oil, Transesterification, Acid Value

\section{INTRODUCTION}

Egypt consumes 81.6 million tons of fuel annually, although its output is not more than 56.4 million tons per year. So, Egypt is resorting to the importation of 25.2 million tons of fuel annually to meet the growing domestic demand for fuel, knowing that this may cost Egypt approximately $\$ 2.5$ billion per year [1]. In addition to this high cost, fuel combustion within motor vehicles may result in emissions that cause environmental pollution such as carbon dioxide $\left(\mathrm{CO}_{2}\right)$, sulfur dioxide $\left(\mathrm{SO}_{2}\right)$ and unburned hydrocarbons $\left(\mathrm{HC}_{\mathrm{S}}\right)[2,3,4]$. But Egypt is forced to do so because the fuel is one of the necessities of daily life [5]. So, it was necessary to look forward to alternatives to petroleum products. Intended alternatives should be economic, friendly to environment and produced from available resources $[6,7]$.

Biodiesel is considered as a biofuel which is produced from natural resources. Biodiesel can be used as a substitute for fossil fuels such as diesel oil. Used cooking oil is a potential raw material for making biodiesel. Its abundant availability can be estimated from an increase in the rate of growth of oil in the last decades. In addition to that, the disposal of used oil causes different problems in sewage network $[8,9,10]$.

The production of biodiesel is developed in the early 1940s [11]. There are at least four ways in which oils and fats can be converted into biodiesel, namely, transesterification, blending, micro emulsions and pyrolysis. Among these, transesterification is the most commonly used methods as it reduces the viscosity of oil [12].

Transesterification reaction is carried out according to the following equation:

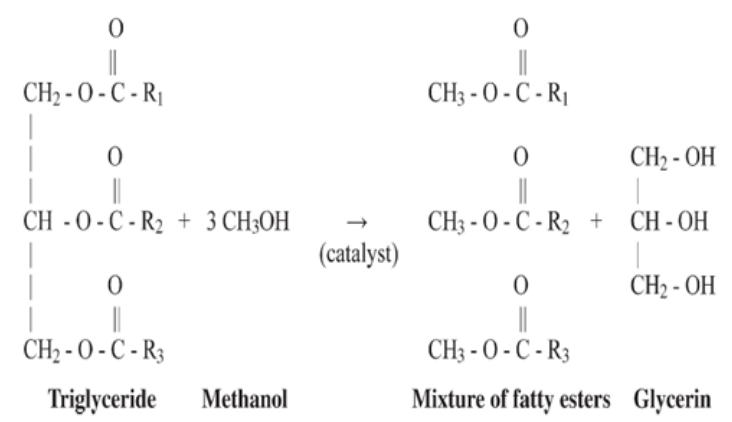

Where, $R_{1}, R_{2}$, and $R_{3}$ are the hydrocarbon chains, also called fatty acid chains [11]

Transesterification reaction depends on some variables such as; moisture and FFA contents, temperature, type of catalyst, molar ratio of alcohol to oil, the degree of refinement of the oil, and agitation speed [11].

At the end of reaction, the glycerol can be separated from biodiesel (methyl esters of fatty acids), because glycerol is insoluble in the esters and has higher density than biodiesel, the separation process of glycerol from biodiesel occurs easily and quickly by settling or centrifuge. Excess amount of methanol will make separation slow. However, this excess methanol is not removed from reaction until separating of glycerol to prevent reversible reaction to occur. Finally, washing of biodiesel is carried out using water then separation of water and drying to enhance quality of produced biodiesel [11].

The aim of this research is to prepare biodiesel from fresh cooking oil and waste cooking oil, characterization of the two produced samples and comparison with European Committee for Standardization EN 14214.).

\section{METHODOLOGY}

\section{A. Materials}

- $100 \%$ fully refined pure blend oil from sunflower and soybean

- Waste cooking oil collected from homes

- Methanol

- Potassium hydroxide 


\section{B. Apparatuses}

- Hot plate

- Mechanical stirrer

- Separating funnel

- Hydrometer

- Ubbelohde viscometer

- Koehler Instruments K14670 TAG Closed Cup Flash Point Tester, 220 - 240V

- Bomb calorimeter

- Infrared spectroscopy (IR spectroscopy)

C. Method

Preparation of biodiesel is carried out on the lab scale.

The acid value is measured for the two types of oil, viscosity and density.

For waste cooking oil, after collection from homes, it is left for $24 \mathrm{~h}$ to settle any solid residues, and then the oil is preheated at $80^{\circ} \mathrm{C}$ for $30 \mathrm{~min}$. Transesterification reaction was carried out by mixing $\mathrm{KOH}$ ( $1 \%$ of oil weight) with methanol (molar ratio of methanol: oil is 6: 1), then , the solution is added to the hot oil (at $60^{\circ} \mathrm{C}$ ) with mechanical stirring at speed $250 \mathrm{rpm}$ and the reaction time was $30 \mathrm{~min}$. The reaction mixture is put in separating funnel and left to $24 \mathrm{~h}$. The glycerol is collected from the bottom, the biodiesel is washed with hot distillate water $\left(\right.$ at $70^{\circ} \mathrm{C}$ ) and put in separating funnel to remove water then dried at $100^{\circ} \mathrm{C}$ for $20 \mathrm{~min}$ to remove moisture.

Biodiesel produced from the two types of oil is characterized by using (IR spectroscopy). Also viscosity, density, flash point and calorific value are measured.

\section{RESULTS AND DISCUSSION}

\section{Oil Characterization}

Characteristics of the two types of oil can be seen in Table1. Because of FFA less than $5 \%$, the feedstock can be transesterified with an alkali catalyst. Used cooking oil has various characteristics depending on many factors, including the type of oil source commodity, duration of use, fried food ingredients and frying temperature. The main characteristics of used cooking oil are the relatively high levels of free fatty acids (FFA), density and viscosity.

TABLE I

CHARACTERISTICS OF OIL

\begin{tabular}{|l|l|l|}
\hline Characteristic property & Fresh oil & Waste oil \\
\hline Density $\left(\mathrm{g} / \mathrm{cm}^{3}\right)$ & 0.917 & 0.916 \\
\hline Viscosity $(\mathrm{Pa} . \mathrm{S})$ & 0.02775 & 0.032 \\
\hline Acid Value(mgKOH/gOil) & 0.2 & 4.48 \\
\hline FFA $(\%)$ & 0.11 & 2.18 \\
\hline
\end{tabular}

\section{Biodiesel Characterization}

Infrared Spectroscopy Analysis

The two prepared biodiesel samples from fresh and waste oil are characterized using FTIR (Fig1). According to Fig1 we noticed the presence of the following biodiesel characteristic peaks [13], stretching absorption peaks were observed of $\mathrm{OH}$, $=\mathrm{CH}$ and $\mathrm{C}=\mathrm{O}$ at $3446,3004,1744 \mathrm{~cm}^{-1}$, respectively.

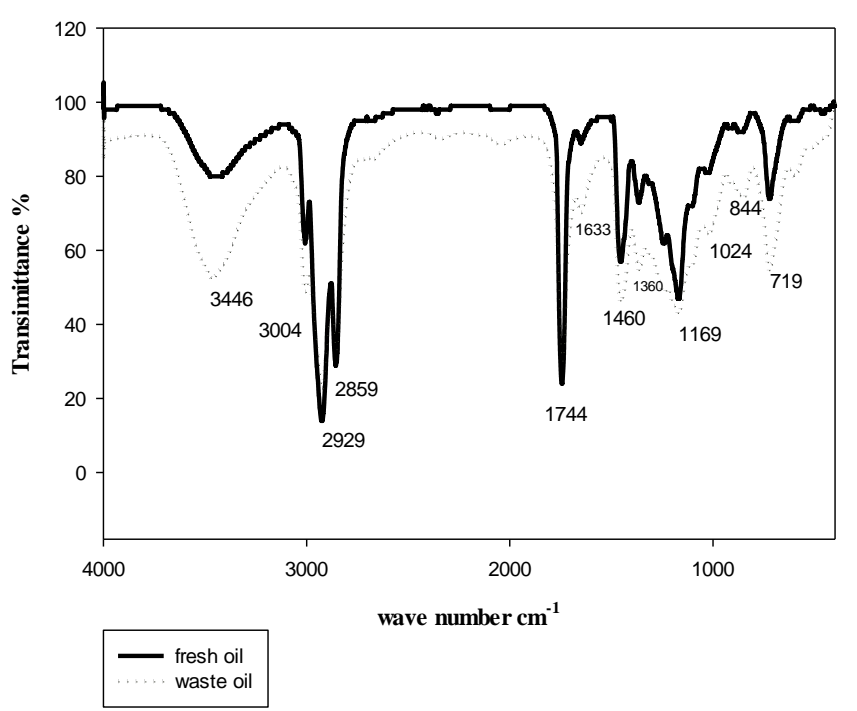

Fig. 1 FTIR of biodiesel prepared from fresh and waste cooking oil.

The asymmetric and symmetric stretching vibration peaks $\mathrm{CH}_{2}$ of group were located at $2929 \mathrm{~cm}^{-1}$ and $2859 \mathrm{~cm}^{-1}$. The anti-symmetric and symmetric stretching vibration absorption peaks of $\mathrm{C}-\mathrm{O}-\mathrm{C}$ were found at $1024 \mathrm{~cm}^{-1}$ and $1169 \mathrm{~cm}^{-1}$. The symmetrical stretching vibrational peak of $\mathrm{C}=\mathrm{C}$ was at 1633 .

\section{Density}

Density of prepared biodiesel samples were measured using hydrometer, fig. 2 at $15^{\circ} \mathrm{C}$ and atmospheric pressure. It was $0.888 \mathrm{~g} / \mathrm{cm}^{3}$ for sample produced from waste cooking oil and $0.9 \mathrm{~g} / \mathrm{cm}^{3}$ for sample produced from fresh oil.

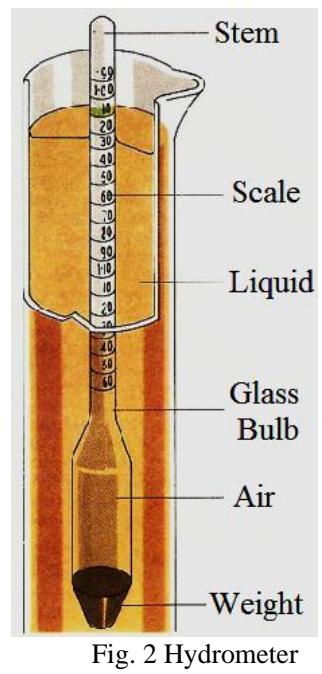

Viscosity

Kinematic viscosity of biodiesel was measured using. Ubbelohde viscometer, fig. 3 . 
TABLE 2

CHARACTERISTICS OF BIODIESEL

\begin{tabular}{|l|l|l|l|}
\hline property & $\begin{array}{l}\text { Biodiesel from } \\
\text { Waste oil }\end{array}$ & $\begin{array}{l}\text { Biodiesel from } \\
\text { fresh oil }\end{array}$ & EN 14214 \\
\hline $\begin{array}{l}\text { Density }(\mathrm{g} / \mathrm{cm} 3) \text { at } \\
15^{\circ} \mathrm{C}\end{array}$ & 0.888 & 0.9 & $0.86-0.9$ \\
\hline $\begin{array}{l}\text { Kinematic } \\
\text { Viscosity }(\mathrm{cSt}) \text { at } \\
40^{\circ} \mathrm{C}\end{array}$ & 4.75 & 4.458 & $3.5-5$ \\
\hline Flash point $\left({ }^{\circ} \mathrm{C}\right)$ & 170 & 170 & $>101$ \\
\hline $\begin{array}{l}\text { Calorific } \\
\text { Value }(\mathrm{MJ} / \mathrm{Kg})\end{array}$ & 37.3 & 37.4 & \\
\hline
\end{tabular}

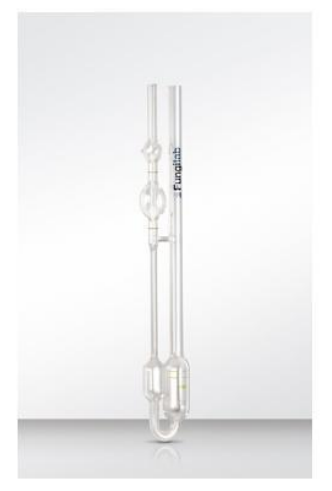

Fig. 3 Ubbeohode viscometer

It was $4.75 \mathrm{~mm}^{2} / \mathrm{s}(\mathrm{cSt})$, for biodiesel prepared from waste cooking oil and $4.458 \mathrm{~mm}^{2} / \mathrm{s}(\mathrm{cSt})$, for biodiesel prepared from fresh oil.

Absolute viscosity also was estimated by using the following relation;

$$
v=\eta / \rho
$$

(v), Kinematic viscosity

$(\eta)$, Dynamic viscosity

$(\rho)$, density

$\eta=v \times \rho=0.039 \mathrm{P}=3.9 \times 10^{-3} \mathrm{~Pa} . \mathrm{s}$ (for biodiesel from waste oil)

$\eta=0.04 \mathrm{P}=0.04 \times 10^{-3} \mathrm{~Pa} . \mathrm{s}$ (for biodiesel from fresh oil).

\section{Calorific Value}

The amount of heat energy produced by combustion of unit mass or volume of fuel is called its calorific value.

Calorific value of solid and liquid fuels can be determined with the help of bomb calorimeter (fig. 4). The basic principles used for determination of calorific value of fuel are that, the known quantity of fuel is burnt, the heat energy liberated is transferred to a medium of known mass and specific heat, and rise in temperature of that medium is measured.

Calorific value was 37.3 and $37.4 \mathrm{MJ} / \mathrm{kg}$ for biodiesel from waste oil and biodiesel from fresh oil respectively. These values are 9\% lower than regular petrodiesel.

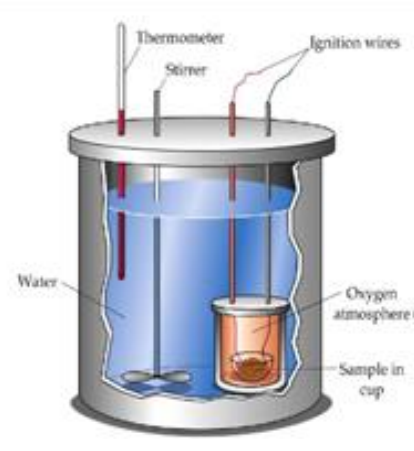

Fig. 4 Bomb calorimeter

Flash Point

The flash point of biodiesel is used as the mechanism to limit the level of unreacted alcohol remaining in the finished fuel. The flash point is important in connection with legal requirements and for the safety precautions involved in fuel handling and storage. The flash point was measured for both biodiesel samples using Koehler Instruments K14670 TAG Closed Cup Flash Point Tester, 220 - 240V, fig. 5. It was $170^{\circ} \mathrm{C}$ for both samples.

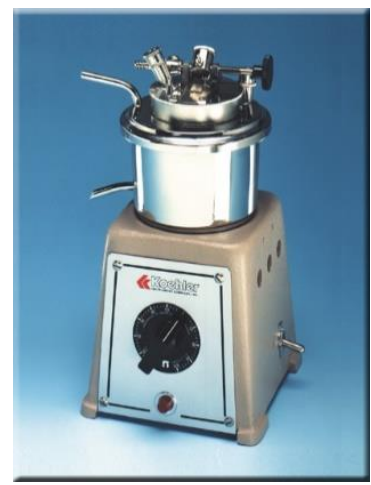

Fig. 4 Flash point tester

All tests applied on prepared biodiesel samples are illustrated in table 2 and compared with EN14214 standard.

EN 14214 is a standard published by the European Committee for Standardization that describes the requirements and test methods for FAME - the most common type of biodiesel.

\section{CONCLUSION}

1. Waste cooking oil as raw material with FFA value of $2.18 \%$ can be converted into biodiesel using the transesterification method directly without going through the esterification process.

2. The specifications of biodiesel prepared from waste cooking oil are comparable with that produced from fresh oil and both of them are within the EN 14214 a standard.

\section{ACKNOWLEDGMENT}

The authors wish to acknowledge the financial and technical support of the Egyptian Academy for Engineering and Advanced Technology, Cairo, Egypt for funding the research project. They also acknowledge the technical support of the Prof. Shereen Mohamed Samir for her technical support. 


\section{V.REFERENCES}

[1] Youm7Novamber Thursday, 2017. Retrieved from www.youm7.com: http://www.youm7.com

[2] N. Said, S.A El-Shatoury, L.F Díaz and M. Zamorano "Quantitative appraisal of biomass resources and their energy", Elsevier, vol. 24(C), pages $84-91$.

[3] N. Sanjel and J. Cue, "ransesterification Kinetics of Waste Vegetable Oil in Supercritical Alcohols", Energies, vol.7, pp. 2095-2106, 2014.

[4] Ma. Fungrui and F. M.Hanna, "Biodiesel production: a review1", Elsevier, vol.70, Pages 1-15, 1999.

[5] A. A. Refaat, N. K. Attia, H. A. Sibak, S. T. El Sheltawy and G. I. ElDiwani, "Production optimization and quality assessment of biodiesel from waste vegetable oil", International Journal of Environmental Science and Technology , vol. 5, pp 75-82, 2007.

[6] D. Krishnan and D. Dass, "A kinetic study of biodiesel in waste cooking oil', African Journal of Biotechnology, vol.11, N41, 2012.

[7] W. Kawentar, A. Budiman, "Synthesis of Biodiesel from SecondUsed Cooking Oil”, Elsevier, vol.32, Pages 190-199, 2013.

[8] H.A.Farag1, Azza El-Maghraby and Nahla.A.Taha, "Kinetic study of used vegetable oil for esterification and transesterification process of biodiesel production', IJCBS, vol. 3, 1-8, 2013.

[9] A. Mendes, "Production of biodiesel from corn oil and ethanol by homogeneous alkali catalyzed transesterification", MSc. Thesis, Department of Chemical Engineering Royal Institute of Technology (KTH) Stockholm, Sweden , 2011.

[10] A.N. Phan and T.M. Phan, "Biodiesel production from waste cooking oil“", Elsevier, vol.87, Pp. 3490-3496, 2008

[11] J. V. Gerpen, “Biodiesel processing and production”, Fuel Processing Technology, Elsevier, vol.86, pp. 1097 - 1107, 2005

[12] A. Matwijczuk, G. Zając, R.Kowalski, M. Jakubowsk and M. Gagos, "Spectroscopic Studies of the Quality of Fatty Acid Methyl Esters Derived from Waste Cooking Oil," Pol. J. Environ. Stud. Vol. 26, No. 6, 2643-2650, 2017.

[13] A. Y. Oyerinde and E. I. Bello, "Use of Fourier Transformation Infrared (FTIR) Spectroscopy for Analysis of Functional Groups in Peanut Oil Biodiesel and Its Blends", British Journal of Applied Science \& Technology, 13(3): 1-14, 2016. 